\title{
Lessons from Three-Dimensional Imaging of Electrical Trees
}

Link to publication record in Manchester Research Explorer

\section{Citation for published version (APA):}

Rowland, S., Chen, S., Zheng, H., Lv, Z., \& Carr, J. (2019). Lessons from Three-Dimensional Imaging of Electrical Trees. Paper presented at IEEE International Conference on Electrical Materials and Power Equipment, Guangzhou, China.

\section{Citing this paper}

Please note that where the full-text provided on Manchester Research Explorer is the Author Accepted Manuscript or Proof version this may differ from the final Published version. If citing, it is advised that you check and use the publisher's definitive version.

\section{General rights}

Copyright and moral rights for the publications made accessible in the Research Explorer are retained by the authors and/or other copyright owners and it is a condition of accessing publications that users recognise and abide by the legal requirements associated with these rights.

\section{Takedown policy}

If you believe that this document breaches copyright please refer to the University of Manchester's Takedown Procedures [http://man.ac.uk/04Y6Bo] or contact uml.scholarlycommunications@manchester.ac.uk providing relevant details, so we can investigate your claim.

\section{OPEN ACCESS}




\title{
Lessons from Three-Dimensional Imaging of Electrical Trees
}

\author{
Simon Rowland ${ }^{1}$, Siyuan Chen ${ }^{1}$, Hualong Zheng ${ }^{1}$, Zepeng Lv $^{1}$ and James Carr ${ }^{2}$ \\ ${ }^{1}$ The School of Electrical and Electronic Engineering, ${ }^{2}$ The School of Materials \\ The University of Manchester \\ Manchester, M13 9PL, UK
}

\begin{abstract}
Electrical trees are artifacts resulting from aging of polymeric insulation in high electrical fields. Whilst there is some debate concerning the mechanism by which they grow, there is no doubt that their growth can lead to the ultimate failure of the host insulation. Studying electrical trees is mainly confined to measurement of associated partial discharges and observing the physical growth of the tree structure optically. This paper reviews developments in observations of the growth of trees in the laboratory. In particular, consideration is given to the benefits of generating three-dimensional replicas of real trees from X-ray computed tomography (XCT) and serial block face scanning electron microscopy (SBFSEM), and how these can facilitate better understanding of tree development mechanisms. It is concluded that both two- and three-dimensional imaging are required, and these need correlating with partial discharge measurements to develop models of tree growth and effective asset management tools.
\end{abstract}

\section{INTRODUCTION}

The failure of high voltage polymeric insulation through the growth of electrical trees is well known. Electrical trees are, as the name suggests, defects which form in the general shape of botanical trees. Essentially these features are gas-filled bifurcated tubules which grow in very high, divergent field regions. Their growth is associated with partial discharges, and can subsequently result in catastrophic failure of the dielectric. In power equipment, the energy of the subsequent discharge through the polymer normally destroys the evidence of tree propagation. However, enough evidence exists of tree growth in equipment which has not yet failed, to understand that these processes occur in commercial systems.

In the laboratory, electrical tree growth is typically studied in unrepresentative geometries. The most common of these is a needle-plane arrangement in which the needle is used to create a high and highly divergent field [1]. An alternative method is to use thin wires to generate the requisite fields [2]. These techniques result in tree inception in short times and at relatively low voltages; of the order of typically $10-20 \mathrm{kV} \mathrm{AC.}$ Such geometries also allow direct observation of tree growth in situ if the materials are transparent. Simultaneous measurements of discharge activity have allowed models of growth behavior to be developed, and consideration of the use of PD data for asset management.

A significant challenge exists in relating laboratory measurements of electrical tree growth in needle-plane configurations across a few mm of insulation, to real systems. The needle-plane geometries are necessary to give rise to very

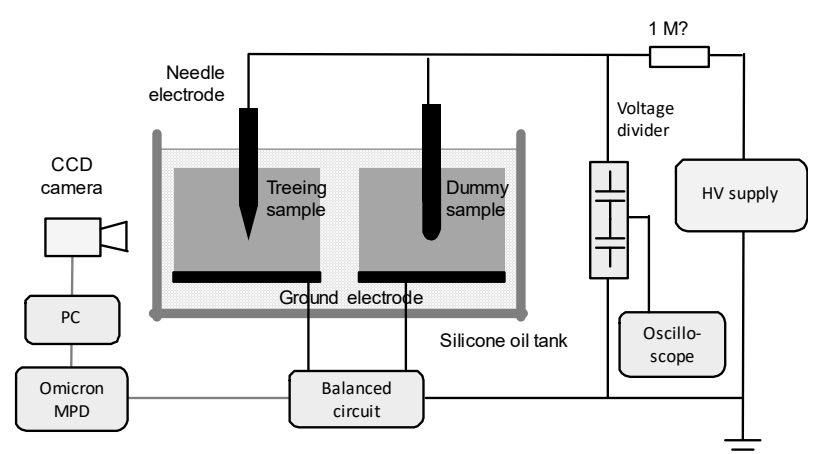

Fig. 1. Typical experimental arrangement enabling optical observation of tree growth and partial discharge measurements

high divergent fields which result in rapid initiation and subsequent growth of trees. However, the fields generated are much higher than in commercial insulation systems. For example if space charge injection is not considered and the insulation considered homogeneous, such samples would give rise to fields of the order $10^{3} \mathrm{kV} / \mathrm{mm}$ at the needle tip $[3,4,5]$. The equivalent value in an $\mathrm{HV}$ cable with no stress-enhancing defect is two orders of magnitude lower.

The second reason to use point-plan geometries in a laboratory context is that it allows control of the location of the growth of an individual tree. Thus not only are tree inception and growth rapid, but in transparent laboratory samples, direct optical observation of tree growth is possible. Simultaneous measurements of discharge activity have allowed models of growth behavior to be developed. Fig. 1 shows a typical arrangement which enables simultaneous optical measurement of tree growth and partial discharge activity. Fig. 2 shows typical resulting images of tree growth.

The main alternative to optical imaging has been the use of SEM. This allows greater detail of the physical aspects of tree growth to be identified, however the technique is destructive and only allows small areas of a tree to be examined $[6,7]$. One limitation of the standard approach of optical imaging is that only two-dimensional images are created and these represent only part of the tree geometry. The depth of field of the imaging system determines how much of a tree is seen. An optical image normally gives a projection of a slice of the tree object. Fig. 2 illustrates that typically a choice is made between observing the whole tree, and observing detail of the tree structure. A further limitation is that only transparent or 

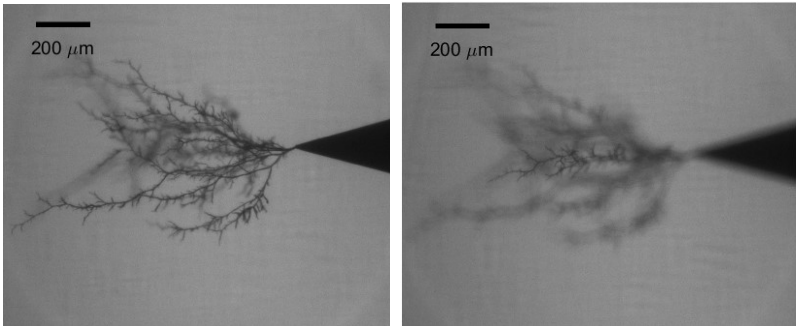

Fig. 2. Typical optical images of a branch type electrical tree grown in LDPE. $12 \mathrm{kV}$ AC was applied for $1410 \mathrm{~s}$ across $2 \mathrm{~mm}$ of insulation. The left-hand image focuses on the centre of the tree, the right-hand image focuses on a branch at the tree periphery.

translucent materials can be studied because these allow direct observation of tree development in situ. Thus whilst 2D images are representative of growth features, they do have limitations, especially in regions of dense tree growth.

Previously optical computed tomography has provided a 3D imaging capability $[8,9]$. More recently the group at The University of Manchester has developed techniques for imaging trees in great detail and in three-dimensions, including in opaque materials. The techniques of serial block face scanning electron microscopy (SBFSEM) and X-ray computerd tomography (XCT) are now briefly reviewed. More detail is provided in [1]. Then advances in imaging of tree growth and morphology are described.

\section{3-DimENSIONAL IMAGING TECHNIQUES}

SBFSEM is a method by which a block-face of material is repeatedly microtomed and imaged (by SEM), thereby generating a sequence of cross-sections of the object. The technique does not allow for metallization between each image. This means that space charge can readily accumulate on the block's surface. To offset this, the SEM is run at a relatively high pressure and the image quality is diminished.

$\mathrm{XCT}$ relies on a series of $2 \mathrm{D}$ projection images being taken as the object containing the feature is rotated [1]. These images are subsequently processed using a reconstruction algorithm to form a virtual 3D replica of the object. Because attenuation contrast is poor for the electrical trees (which are essentially voids in the polymer), contrast is enhanced by the shift in the phase of the X-rays as they pass through the object.

In each case (SBFSEM and XCT) a $3 \mathrm{D}$ replica of the tree is generated from which characteristics can be obtained [10]. Invariably it is a combination of techniques which gives the full description of the electrical tree [11].

\section{KEY BENEFITS OF 3-DimENSIONAL IMAGING}

A. Determination of tree morphology - structural resolution The trees shown in Fig. 2, which would normally be described as branch trees, have been well captured by the optical camera with a judicious choice of lens. A clear understanding of the $3 \mathrm{D}$ structure is possible from the $2 \mathrm{D}$ image presented. However, 2D imaging cannot give a clear idea of the internal structure for higher density tree structures such as the bush trees shown in Figs. 3 and 4. a)

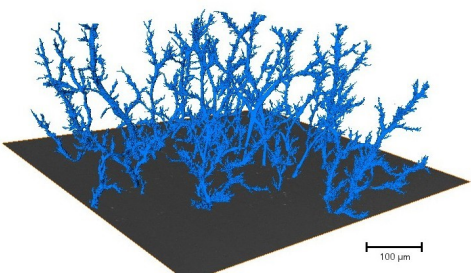

b)

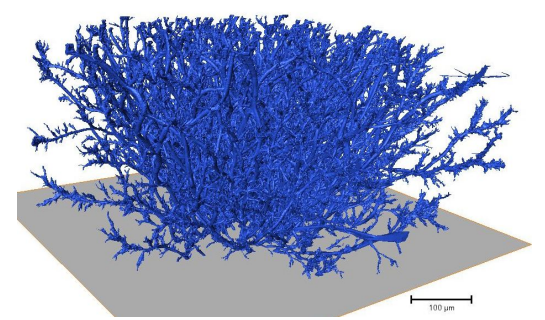

Fig. 3. Examples of SBFSEM reproductions of bush trees, which allow internal details to be analyzed. Images (a) and (b) are from different parts of the same tree. (a) is closer to the tree top, and (b) closer to the needle tip. The scale bars are $100 \mu \mathrm{m}$ in length.

Computer tomography allows the user to image which part or cross-section is of most interest. Fig. 3 and Fig. 4 show the transparency this can bring to an otherwise inaccessible view. Quantitative descriptors are also readily determined by software. Examples are: fractal dimension, number of branches, number of nodes, segment length, branch angle, branch tortuosity, channel size, tree volume, and tree surface area. These are more deeply considered in [10].

The description of fractal dimension is worthy of more consideration because it is widely used to describe 2D images, and so it is discussed in more detail in the following section.

A final and important ability for the researcher using 3D reconstructions of objects, is the ability to look at the nature of the overall structure. Two examples are: the identification of the development of a large void within a bush tree at the needle tip [11], and the merging of two branches within a tree. Both of these allow interpretation of the treeing process, which would not have been possible with 2D imaging alone.
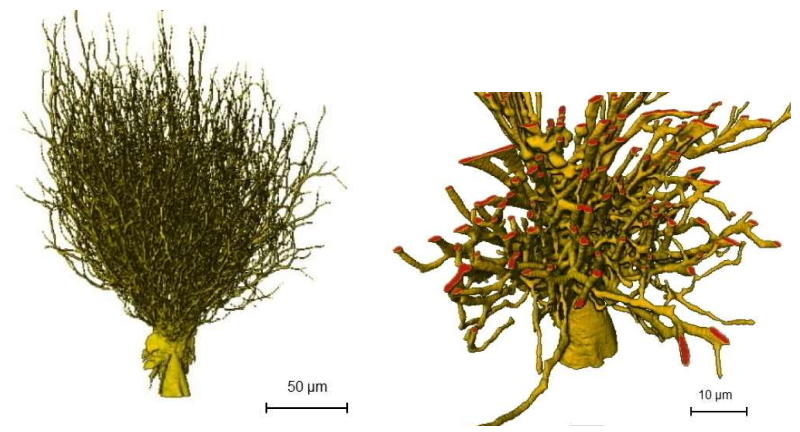

Fig 4. On the left is a 3D XCT reconstruction of a bush tree in epoxy resin. The right-hand image is a section of the reconstruction adjacent to the needle, enlarged by a factor of $\sim 5$ compared to the image of the

whole tree. The areas where the top surface of the section cuts through tree branches (air) are colored red for clarity. 
Identification of the destruction of tree structure close to a needle after long periods of aging is important for two reasons. Firstly, the nature of the discharges emanating from the needle may change if they are not directly into a well-formed tree channel (i.e. they are no longer constrained by the channel walls) [12]. Secondly, such a characteristic may not reflect the development of a tree in a service situation, where the origin is not a metallic protrusion. This might imply that the latter stages of this type of laboratory tree development are not helpful for development of asset management tools.

The location where two branches have merged is given in Fig. 5. If it is assumed that tree growth is field driven, the merging of tree branches implies the branches are not at the same potential. In other words, the tree was non-conductive at the time of the branches merging. This is an important conclusion when considering tree growth dynamics.

\section{B. Determination of tree morphology - fractal dimension}

The most common quantitative method to characterize the geometry of a tree is to determine the fractal dimension $D_{f}$ of a $2 \mathrm{D}$ projection (optical image) by the box-counting method [13]. This is a practical and efficient method which quantifies how a tree fills the space it occupies. $D_{f}$ is determined by dividing the area into squares (or a 3D volume into cubes) with side length $\mathrm{r}$, and the number of squares required to cover the shape $N_{(r)}$ is determined. This is done for a range of values of r. If $N_{(r)} \sim r^{-D_{f}}$, then $D_{f}$ is the fractal dimension. It is widely considered that branch trees are associated with $1<\mathrm{D}_{\mathrm{f}}<2$, and bush trees have $D_{f}>2$. However, it is clear from the images of Figs. 3 and 4 that high density trees, such as bush trees cannot have their structure established from 2D images, and fractal indices in such cases must be determined from 3D images. Schurch et al [10] suggest that in trees with three-dimensional values of fractal index of less than 2, a simple linear relationship exists between the two- and three-dimensional values such that:

$$
{ }^{3 D} D_{f}={ }^{2 D} D_{f}+0.2 \text { if }{ }^{2 D} D_{f}<1.75
$$

It is suggested that $2 \mathrm{D}$ values of fractal dimension for dense bush trees or values of ${ }^{2 D} D_{f}>1.8$ should be treated with caution.

\section{Tree initiation conditions}

In typical laboratory conditions 3D assessment of initiation conditions is not entirely necessary because the geometric conditions are designed to be symmetrical. However, it is clear

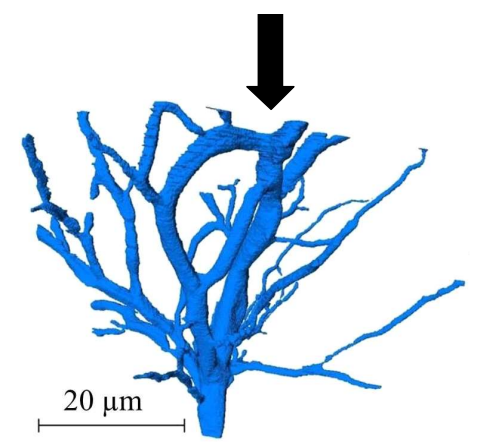

Fig. 5. XCT reconstruction showing two branches merged at the location identified by the arrow.

The initiating needle is at the bottom of the image (not shown). that where metallic defects are the initiating points, the boundary between the metal and polymer is critical. In particular voids at the interface control both inception and subsequent tree growth [12]. Optical microscopy is not capable of identifying very thin air gaps of $\sim 10 \mu \mathrm{m}$ between needles and the polymer, so for this reason X-ray imaging has very high value in studying inception sites. Experience in Manchester suggests that $2 \mathrm{D}$ imaging is adequate for examination of air gaps at the needle polymer interface. Nonetheless, very early tree growth is well captured by XCT as shown in Fig. 6.

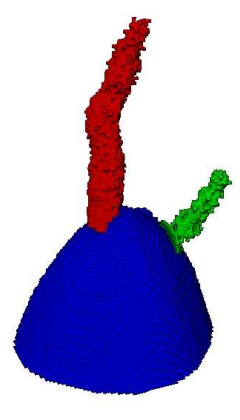

Fig. 6. Early stages of tree growth imaged by XCT. The two tree branches (red and green) and needle tip (blue) are colored for emphasis. The scale bar is $10 \mu \mathrm{m}$ in length

\section{Imaging in filled polymers}

Optical imaging cannot be used for opaque materials. The most important group of these are filled polymers. Thermoset resins and EPRs for example, when used as high voltage insulation, include high levels of inorganic filler. The fillers may improve properties such as: mechanical and electrical strength, improved surface tracking resistance and thermal conductivity. They may also reduce the cost of the polymer. In the laboratory, such fillers obscure trees which grow in the sample, and which would otherwise be observable optically. For this reason virtually all published tree growth experiments are on unfilled materials. However, there is no reason to imagine that the characteristics of tree growth in unfilled material match those of the filled material.

The technique of SBFSEM does not work well for filled materials, because the microtoming drags the filler particles across the surface of the test piece at each cut. The resulting scratches are of similar size to tree features and so noisy images result. The only technique presently able to observe trees in highly filled materials is XCT. In the last five years this technique has developed rapidly, gradually overcoming the technical difficulties of imaging micron-, and sub-micronscale voids in polymers with high density filler particles dispersed in the polymer. The team in Manchester has recently shown that, using a synchrotron source, trees in highly filled materials can be imaged. Early results showing tree growth [14] have now been improved and will be published shortly. Fig. 7 shows an example of a $3 \mathrm{D}$ replica of a tree imaged in $15 \%$ filled epoxy resin. The discontinuities in the tree branches suggest the imaging technique does not yet have the resolution to image the finest channels in the structure. 


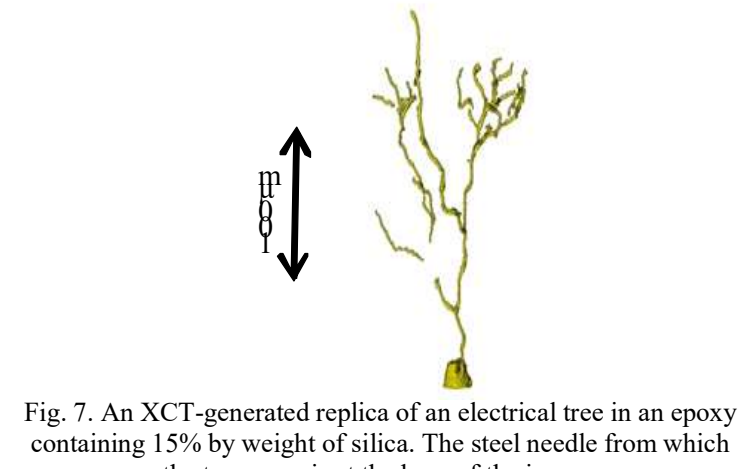

Fig. 7. An XCT-generated replica of an electrical tree in an epoxy
containing $15 \%$ by weight of silica. The steel needle from which the tree grew is at the base of the image.

\section{DISCUSSION}

Three-dimensional imaging is relatively slow and costly compared to traditional two-dimensional optical techniques. However, it can bring a distinct understanding and characterization of tree growth. The use of SBFSEM and XCT has been shown to create excellent reproductions of electrical trees grown under laboratory conditions. The challenges of imaging trees in filled materials with XTC are gradually being overcome, and unique observations of tree growth in microfilled materials are now available.

With any techniques, great care should be taken with interpretation of images. It is important to understand the resolution of the technique for the feature to be examined. So because of its greater transparency, smaller features are observable using optical microscopy in unfilled epoxy resin than in translucent LDPE for example. All imaging methods are instrument- and user-dependent and the choice of instrument determines the size of sample that can be examined, and the resolution of imaging. The blue features in Fig. 8, for example, are visible with nano-XCT, whereas the green image is all that is seen in micro-XCT.

Microtoming tree-containing samples and then using SEM gives great detail, but only of small areas of a tree. SBFSEM allows such features to be assembled into a full image. However, it should be noted that because of the relatively high pressure of the SBFSEM and space charge accumulation, the image quality from that technique is not as good as from traditional SEM.

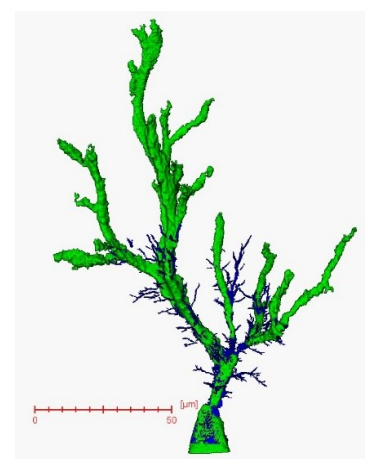

Fig. 8. An XCT-generated replica of an electrical tree in an epoxy. The blue parts are visible with nano-XCT but not with micro-XCT.

\section{CONCLUSION}

A review of the opportunities afforded by $3 \mathrm{D}$ imaging techniques has been provided. In particular XCT has unique advantages in imaging trees in opaque materials. New opportunities using XCT and SBFSEM have been identified to enable accurate characterization of trees. Features not otherwise visible can be seen in both bush trees and trees grown in optically opaque materials for the first time. 3D imaging has an important part to play alongside $2 \mathrm{D}$ imaging and these need correlating with partial discharge measurements to provide tools required for interpreting online measurements in power system plant.

\section{ACKNOWLEDGMENT}

The authors acknowledge EPSRC for support through 'Novel Composite Dielectric Structures with Enhanced Lifetimes' EP/M016234/1 and Supergen HubNet EP/I013636/1.

\section{REFERENCES}

[1] R. Schurch, S. M. Rowland, R. S. Bradley and P. J. Withers, "Imaging and Analysis Techniques for Electrical Trees using X-ray computed tomography" IEEE Transactions on Dielectrics and Electrical Insulation, Vol. 21 , Iss. 1, pp.53-63, 2014

[2] X. Chen, A. R. Mantsch, L. Hu, S. M. Gubanski, J. Blennow, C. Olsson, "Electrical treeing behavior of DC and thermally aged polyethylenes utilizing wire-plane electrode geometries" IEEE Trans on Dielectrics and Electrical Insulation, Vol. 21, pp. 45 - 52, 2014

[3] S. M. Rowland, R. Schurch, M. Pattouras and Qi Li, "Application of FEA to Image-based Models of Electrical Trees with Uniform Conductivity", IEEE Transactions on Dielectrics and Electrical Insulation, Vol. 22, Iss. 3, pp. 1537-1546, 2015

[4] R. W. Hare and R. M. Hill, "Space charge in insulators with needle plane geometry", J. Phys. D. Appl. Phys., Vol. 24, pp. 398-406, 1991

[5] L. Cisse, S. S. Bamji and A. T. Bulinski, "Electric field calculations for needle-plane geometry and space charge in polyethylene", IEEE Trans on Dielectrics and Electrical Insulation, Vol. 10, pp. 176-180, 2003

[6] A. S. Vaughan, I. L. Hosier, S. J. Dodd, and S. J. Sutton, "On the structure and chemistry of electrical trees in polyethylene", J. Phys. D. Appl. Phys., Vol. 39, No. 5, pp. 962-978, 2006

[7] T. Iizuka, Y. Ohki, and T. Tanaka, "Effects of coupling agent and filler dispersion on V-t characteristics of epoxy/silica nanocomposites" Proc. Int. Symp. on Electrical Insulating Materials, Japan, pp. 60-63, 2008

[8] H. Uehara, K. Kudo "The 3-D fractal analysis of electrical trees using a serial sectioning method and a CT method", IEEE Int. Conf. on Conduction and Breakdown in Solid Dieledrics, Sweden, 309-312, 1998

[9] M. Yanagiwara and N. Yoshimura, "Three dimensional measurement system of treeing using an image processing", Proc of the $3^{\text {rd }}$ Int. Conf. on Properties and Applications of Dielectric Materials, Tokyo, 1991

[10] R. Schurch, J. Ardila-Rey, J. Montana, A. Angulo, S. M. Rowland, I. Iddrissu, R. S. Bradley, "3D Characterization of Electrical Tree Structures" Accepted for publication in IEEE Trans on Dielectrics and Electrical Insulation

[11] R. Schurch, S. M. Rowland, R. S. Bradley and P. J. Withers, "Comparison and Combination of Imaging Techniques for Three Dimensional Analysis of Electrical Trees" IEEE Transactions on Dielectrics and Electrical Insulation Vol. 22, Iss. 2, pp. 709-719, 2015

[12] H. Zheng, S. Rowland, F. Liu, and Z. Lv "The Influence of an Air Gap at the Needle/Polymer Interface on Electrical Tree Growth" Accepted for publication in 2nd Int. Conf. on Electrical Materials and Power Equipment (ICEMPE), Guangzhou, 2019

[13] K. Kudo, "Fractal analysis of electrical trees," IEEE Trans. Dielectr. Electr. Insul., vol. 5, no. 5, pp. 713-727, 1998

[14] R. Schurch, S. M. Rowland, R. S. Bradley, T. Hashimoto, G. E. Thompson and P. J. Withers "Three dimensional imaging of electrical trees in micro- and nano-filled epoxy resin", IEEE Conf. Electrical Insulation and Dielectric Phenomena, Des Moines, pp. 39-42 2014 